\title{
Basophil Activation Test: Old and New Applications in Allergy
}

\author{
Oliver Hemmings ${ }^{1,2,3} \cdot$ Matthew Kwok ${ }^{1,2,3} \cdot$ Richard McKendry ${ }^{1,2,3} \cdot$ Alexandra F. Santos M $^{1,2,3,4}$
}

Published online: 15 November 2018

(C) The Author(s) 2018

\begin{abstract}
Purpose of Review The basophil activation test (BAT) using flow cytometry has supplanted traditional methods of measuring basophil degranulation using histamine and other mediator release, and can be used for clinical applications as well as to explore the immune mechanisms of effector cell response to allergen. This review discusses the advancements made in clinical, diagnostic and laboratory research of allergy utilizing an ever-evolving BAT.

Recent Findings Being an in vitro surrogate of the allergic reaction that happens in vivo in the sick patient, the BAT can be used to support the diagnosis of various allergic conditions, such as food, drug, respiratory and insect venom allergies, and the assessment of clinical response to allergen-specific immunotherapy and other immunomodulatory treatments. The BAT can also be used for research purposes to explore the mechanisms of allergy and tolerance at the level of the basophil, for instance by manipulating $\operatorname{IgE}$ and IgG and their receptors and by studying intracellular signalling cascade in response to allergen.

Summary This review covers the applications of the BAT to the clinical management of allergic patients and the increased understanding of the mechanisms of immune response to allergens as well as technological advancements made in recent years.
\end{abstract}

Keywords Basophil activation test $\cdot$ Diagnosis $\cdot \operatorname{IgE} \cdot \operatorname{IgG} \cdot$ Allergy $\cdot$ Immunotherapy

\section{Introduction}

In the past, testing the basophil response to allergen was focused on the measurement of mediators released by cells into the supernatant in vitro, including histamine and leukotrienes $[1,2]$. Technical and analytical limitations, the relatively large blood volume required and low sensitivity $[1,3]$, together with the discovery and widespread use of flow cytometry techniques have opened scope for new basophil assays, like the basophil activation test (BAT) $[2,4 \bullet, 5]$. The BAT is a

This article is part of the Topical Collection on Immunologic/Diagnostic Tests in Allergy

Oliver Hemmings, Matthew Kwok, and Richard McKendry contributed equally to this manuscript

Alexandra F. Santos

alexandra.santos@kcl.ac.uk

1 Department of Women and Children's Health (Paediatric Allergy), School of Life Course Sciences, Faculty of Life Sciences and Medicine, King's College London, London, UK

2 Peter Gorer Department of Immunobiology, School of Immunology and Microbial Sciences, Faculty of Life Sciences and Medicine, King's College London, London, UK functional assay that measures $\operatorname{IgE}$ function, i.e. its ability to induce the activation of basophils in the presence of allergen. The BAT has the potential to closely replicate in vitro type I hypersensitivity reactions, which develop in vivo when allergic individuals are exposed to the allergen, and thus can have clinical applications in the diagnosis and prognosis of allergic disease, alongside research applications. In this review, we will cover the main principle technical aspects related to the performance of the BAT, its clinical applications across different allergic conditions and the use of BAT to explore the immune
3 MRC and Asthma UK Centre in Allergic Mechanisms of Asthma, London, UK

4 Children's Allergies Department, Guy's and St. Thomas' NHS Foundation Trust, St. Thomas' Hospital, Westminster Bridge Road, London, UK 
mechanisms of allergy and tolerance, in order to improve our understanding of the development of allergic conditions and potentially find new targets for treatment and prevention.

\section{The Basophil Activation Test: Principles and Technical Aspects}

The BAT uses flow cytometry to measure the expression of activation markers on the surface of basophils that are upregulated following the cross-linking of $\operatorname{IgE}$ antibodies bound to the high-affinity $\operatorname{IgE}$ receptor ( $\mathrm{Fc} \varepsilon \mathrm{RI}$ ) that result from allergen or anti-IgE stimulation. There are a number of different markers which can be used to identify basophils and to quantify their activation by flow cytometry (Table 1 ). In addition to the expression of cell surface markers, basophil activation can also be studied by looking at the phosphorylation of certain intracellular molecules, such as p38 mitogen-activated protein kinase (MAPK) or signal transducer and activator of transcription (STAT) 5, which are part of the signalling cascade downstream of IgE and its high-affinity receptor [21, 22]. Other methods of assessing basophil activation, using technologies such as CYTOF [23•] and fluorescent-avidin [24], have been suggested.

The BAT can be performed using whole blood or isolated peripheral blood mononuclear cells (PBMCs), which include the basophils. PBMC isolation can be performed using density gradient separation and additional negative selection using magnetic particles allows enrichment for basophils [25]; however, there is an increased risk of cell loss from the centrifugation steps and excessive handling of the cells may cause background activation [26]. Flow cytometry and fluorescent staining techniques have allowed for the specific investigation of basophils in whole blood without the need for further manipulation [3]. Additionally, the use of whole blood as opposed to isolated basophils may be more physiological and more closely resemble the in vivo environment of blood basophils, with other factors present, such as blocking antibodies, that may play a role in the allergic or non-allergic phenotype of individuals [26].

Whole blood BAT should ideally be performed within $4 \mathrm{~h}$ of blood collection to maximize viability and functionality of basophils [27, 28], as basophil reactivity decreases considerably over time [29]. If a longer time is needed between blood collection and the performance of the BAT (e.g. multicenter studies or clinical centers located far from reference laboratory), blood can be processed within $24 \mathrm{~h}$ [30]. Mukai and colleagues [23•] have shown that BAT performed on blood stored in heparin at $4{ }^{\circ} \mathrm{C}$ at $4 \mathrm{~h}$ and at $24 \mathrm{~h}$ following blood collection did not show significant differences and that transportation during this period of time did not significantly affect the results. Collection of whole blood for BAT is usually done in heparin; other anticoagulants such as ethylenediaminetetraacetic acid (EDTA) or acid citrate dextrose (ACD) can prevent

Table 1 Basophil identification and activation markers

\begin{tabular}{|c|c|c|c|c|}
\hline & Marker & Cell expression & Description and gating strategy & Reference \\
\hline \multirow[t]{5}{*}{$\begin{array}{l}\text { Identification } \\
\text { markers }\end{array}$} & CCR3 & Basophils, mast cells, Th2 lymphocytes & $\begin{array}{l}\text { Stable marker for identification, may need further differentiation } \\
\text { from other cells such as use of CD3 }\end{array}$ & {$[6-9]$} \\
\hline & CD203c & $\begin{array}{l}\text { Basophils, mast cells, } \mathrm{CD} 34^{+} \\
\quad \text { progenitor cells }\end{array}$ & $\begin{array}{l}\text { Widely used identification marker and expressed in low levels of } \\
\text { resting cells. Upregulation has been reported to be representative } \\
\text { of piecemeal degranulation }\end{array}$ & {$[10,11]$} \\
\hline & CD123 & Basophils, plasmacytoid dendritic cells & $\begin{array}{l}\text { Highly expressed in these cells; HLA-DR can be used to } \\
\text { differentiate between HLA-DR }{ }^{+} \text {dendritic cells }\end{array}$ & {$[12,13]$} \\
\hline & $\operatorname{IgE}$ & Basophils, monocytes, dendritic cells & $\begin{array}{l}\text { Other cells expressing high affinity IgE receptor FcERI can be } \\
\text { differentiated by also using HLA-DR. High variability in } \\
\text { individuals has been reported }\end{array}$ & {$[6,14]$} \\
\hline & CRTH2 & $\begin{array}{l}\text { Basophils, eosinophils, Th2 } \\
\text { lymphocytes }\end{array}$ & $\begin{array}{l}\text { Differentiation from eosinophils by side scatter or T lymphocytes by } \\
\text { CD3 is reported }\end{array}$ & {$[15]$} \\
\hline \multirow[t]{6}{*}{$\begin{array}{r}\text { Activation } \\
\text { markers }\end{array}$} & CD63 & $\begin{array}{l}\text { Basophils, mast cells, platelets, } \\
\text { macrophages }\end{array}$ & $\begin{array}{l}\text { Widely used activation marker and an accurate marker of } \\
\text { anaphylactic degranulation }\end{array}$ & $\begin{array}{c}{[7,11,16} \\
17 \bullet \bullet]\end{array}$ \\
\hline & $\begin{array}{l}\text { CD107a, } \\
\text { CD107b }\end{array}$ & $\begin{array}{l}\text { Various cell types including basophils, } \\
\text { mast cells, T cells and NK cells }\end{array}$ & \multirow{3}{*}{$\begin{array}{l}\mathrm{CD} 107 \mathrm{a} \text { and CD107b was found to be only expressed by ac } \\
\text { basophils and its upregulation was similar to CD63. CD13 } \\
\text { CD164 has an expression profile comparable to CD203c }\end{array}$} & \multirow[t]{3}{*}{ [18] } \\
\hline & CD13 & Basophils, myeloid cells & & \\
\hline & CD164 & Basophils, CD $34^{+}$progenitor cells & & \\
\hline & CD69 & $\begin{array}{l}\text { Basophils, lymphocytes, neutrophils, } \\
\text { monocytes, eosinophils }\end{array}$ & $\begin{array}{l}\text { Expressed progressively when stimulated with IL-3; however, found } \\
\text { to be weakly expressed to IgE mediated stimulation }\end{array}$ & {$[19,20]$} \\
\hline & $\begin{array}{l}\text { p38 MAPK, } \\
\text { STAT5 }\end{array}$ & Various cell types & $\begin{array}{l}\text { Basophilic phosphorylation of intracellular molecules can } \\
\text { alternatively be used to measure basophil activation }\end{array}$ & {$[21,22]$} \\
\hline
\end{tabular}


basophil degranulation [4•]. EDTA, for example, can chelate calcium, which can be reversed by the addition of extracellular calcium in later incubation steps; however, in possibly different concentrations than the physiological concentration in the original blood sample. Priming of basophils with IL-3 can help to enhance IgE-mediated CD63 responses to allergen but can induce non-specific upregulation of CD203c and p38 MAPK signalling pathways [21, 28, 31]. Sturm and colleagues also observed that pre-warming samples and reagents at $37^{\circ} \mathrm{C}$ for $10 \mathrm{~min}$ before performing BAT to enhance basophil responses had no effect [28].

Allergen source is another critical factor in both clinical and research applications of the BAT. Allergen stimulants range from crude extracts to recombinant or purified single allergen sources. Standardized preparations are recommended when comparing performance data from different laboratories and when performing tests over time [4•]. The availability of recombinant allergens for testing in the BAT may be limited but they have the greatest stability and consistency compared to crude allergen or extracts and can help improve diagnostic accuracy in some cases $[14,32]$. To test for drug allergy, pure drug preparation used for parenteral administration is preferred and dilutions should be prepared shortly before performing the BAT [4॰].

Testing a dose-response consisting of at least five different allergen concentrations, for instance in 10-fold increments, is recommended as opposed to a single allergen concentration given the variability of basophil responses between individuals. This variability is partly due to the complexity of antigens, varying affinity of IgE for allergen epitopes and intrinsic basophil sensitivity $[2,33]$. Consequently, the dose-response profile can vary markedly from a typical bell-shaped doseresponse curve [2]. The results of the BAT from a doseresponse curve can be expressed as basophil reactivity, basophil sensitivity or both [33]. Basophil reactivity can be measured using \%CD63+ basophils at a given concentration or using CD-max, i.e. the concentration at which maximal basophil activation occurs. Conversely, basophil sensitivity can be expressed as either EC50 (the concentration at which 50\% of maximal basophil response occurs) or CD-sens (defined as the inverse of EC50 multiplied by 100 and this can be calculated from the slope of the dose-response curve) [34]. The area under the dose-response curve has been used more recently to assess basophil reactivity and sensitivity simultaneously [35].

About $5-10 \%$ of individuals have non-responding basophils, in which no upregulation of CD203c or CD63 occurs in response to IgE-mediated allergen stimulation, but only to non-IgE-mediated stimulants [26]. It is therefore recommended to include both IgE-dependent (e.g. anti-IgE or anti-FceRI) and IgE-independent (e.g. fMLP or ionomycin) positive controls in the BAT [36]. Furthermore, a negative control consisting of stimulation buffer alone should also be included to assess the level of background or spontaneous activation of basophils [26]. If IL-3 is used, an additional control for IL-3 in the stimulation buffer should be included.

The transition of the BAT from the research laboratory to clinical practice is dependent on the standardization and quality assurance of the laboratory procedure, flow cytometry and data analyses, in addition to the clinical validation of the diagnostic performance of BAT to different allergens $[4 \cdot, 14]$. Automation of flow cytometry data analyses can help improve the efficiency and transparency of analyses and the reproducibility of the data $[37 \cdot \bullet]$. Bioinformatics tools and resources including raw data are increasingly becoming available to the public, which can further facilitate standardization and sharing of methodology [14]. Currently, an international task-force from the EAACI has gathered experts with extensive experience in the clinical application of the BAT to start addressing the quality assurance of the BAT. The assessment of the costeffectiveness and impact on clinical-decision making is likely to be central to the regulatory approval of the BAT for clinical use and deserves further research [33].

\section{Clinical Applications of the Basophil Activation Test}

The clinical history is the key factor to accurately diagnose allergy. With a likely culprit allergen and an immunologic mechanism in mind, the documentation of the presence of $\operatorname{IgE}$ or a cell-mediated reaction using serum-specific $\operatorname{IgE}$ (sIgE) and/or skin testing supports the diagnosis [38-42]. Despite being well-established, skin testing and SIgE have practical limitations - for instance, skin testing requires intact skin and anti-histamine cessation, and both skin testing and sIgE detect sensitization, which does not equate to clinical allergy [43]. If the diagnosis is equivocal following the clinical history and skin and/or sIgE testing, a provocation test or challenge needs to be performed under clinical supervision (e.g. oral food challenge in food allergy, drug provocation test in drug allergy). The challenge is labour and resource-intensive and often stressful for the patient as it has the risk of inducing allergic reactions, including cutaneous, oral, gastrointestinal, respiratory and cardiovascular symptoms $[44 \bullet, 45 \bullet \cdot, 46 \bullet$. Across all types of allergic disease, an in vitro assay that could represent the allergic reaction in vivo better than skin testing and SIgE would be most useful. In IgE-mediated allergy, the BAT emerges as such as it can potentially reproduce the immediate-type allergic reaction in the test tube.

\section{BAT in the Diagnosis of Food Allergy}

Skin prick test (SPT) and SIgE have high sensitivity but low specificity to diagnose food allergy. Although $95 \%$ positive 
predictive value (PPV) cutoffs have been determined for certain allergens and certain populations with enhanced specificity, the majority of patients assessed for food allergy have results below such cutoffs, and even when using specific IgE to allergen components, the results can be equivocal. The BAT has shown to be more accurate than IgE sensitization tests and able to distinguish individuals that were clinically allergic from those who were tolerant albeit sensitized in various studies, with high specificity ranging between 75 and $100 \%$ and high sensitivity ranging between 77 and $98 \%$ [45••, 47, 48]. In a large peanut allergy study, BAT was externally validated in a new independent population and showed $100 \%$ specificity [45••]. This high specificity means that a positive BAT to peanut confirmed peanut allergy and dispensed oral food challenge (OFC). Thus the reduction in OFC was mainly a reduction in positive $\mathrm{OFC}$, sparing patients from experiencing allergic reactions [45••]. Recent studies have shown that BAT has high specificity in diagnosing allergy to tree nuts, higher than SPT and sIgE to individual allergens for instance in the case of hazelnut allergy [49]. BAT to single allergens can enhance the diagnostic performance of BAT for some food allergies, such as Ara h 2 and Ara h 6 to diagnose peanut allergy [50], with the caveat that some allergic patients may not be sensitized to the allergens being used as stimulants in the BAT, potentially leading to false negative results in these selected cases.

BAT also has utility that goes further beyond diagnosing and monitoring food allergy. It can also relate to the severity of allergic reactions in that patients with more severe reactions show a greater proportion of activated basophils and patients reacting to trace amounts of the allergen show a greater basophil sensitivity, i.e. their basophils start reacting at lower allergen concentrations $[51,52,53]$.

\section{BAT in the Diagnosis of Drug Allergy}

The diagnosis of drug allergy poses additional challenges compared with the diagnosis of allergy to large protein allergens, such as food and airborne allergens. The clinical phenotype of allergic reactions to drugs is more diverse and the underlying mechanisms can fall into types of hypersensitivity beyond type I hypersensitivity. However, diagnostic difficulties specific to drug allergy also pose additional opportunities for improved methods for testing such as the BAT. For instance, skin testing to drugs, particularly intradermal testing, incurs a significant risk of systemic reactions, including anaphylaxis. Furthermore, sIgE testing is not possible to both the native drug and all its metabolites, many of which maybe the culprits for the allergic reaction [54]. Drug provocation tests (DPTs) to certain drugs are impractical or unethical particularly in the context of anaphylaxis under general anaesthesia. Therefore, in these instances, BAT may be the only diagnostic tool available and is often a cheaper and safer alternative to other tests $[55,56]$.

Several studies over the last 15 years have reported the diagnostic accuracy of BAT for allergy to a range of drugs including betalactams [36, 57, 58], quinolones [59-61] and neuromuscular blocking agents (NMBAs) [62, 63] (Table 2). More recently, BAT has shown to be useful in the diagnosis of omeprazole allergy: skin tests alone showed sensitivity of $66.7 \%$ and specificity of $100 \%$, while the addition of the BAT increased the sensitivity to $73.8 \%$ without a reduction in specificity [71]. BAT to clavulanic acid showed high positive predictive value (PPV) in a recent study and thus added value to BAT to amoxicillin when managing patients with suspected amoxicillin-clavulanic acid allergy [72•]. It has

Table 2 Diagnostic performance of the basophil activation test on different allergic conditions

\begin{tabular}{|c|c|c|c|c|c|c|}
\hline \multicolumn{2}{|l|}{ Allergen } & \multirow{2}{*}{$\begin{array}{l}\begin{array}{l}\text { Number of } \\
\text { participants }\end{array} \\
104\end{array}$} & \multirow{2}{*}{$\begin{array}{l}\text { Cutoff values } \\
\geq 4.78 \% \text { CD63+ }\end{array}$} & \multirow{2}{*}{$\begin{array}{l}\text { Sensitivity } \\
(\%)\end{array}$} & \multirow{2}{*}{$\begin{array}{l}\begin{array}{l}\text { Specificity } \\
(\%)\end{array} \\
96\end{array}$} & \multirow{2}{*}{$\begin{array}{l}\text { Publication } \\
{[45 \bullet \bullet]}\end{array}$} \\
\hline Food & Peanut & & & & & \\
\hline & Cow's milk & 50 & $\mathrm{CD} 203 \mathrm{c} \mathrm{SI} \geq 1.9$ & 89 & 83 & {$[64]$} \\
\hline & Egg & 67 & $\geq 5 \% \mathrm{CD} 63+$ & 77 & 100 & {$[48]$} \\
\hline \multirow[t]{3}{*}{ Drug } & BetaLactams (various) & 24 & $\geq 5 \% \mathrm{CD} 63+$ & 55 & 80 & {$[36]$} \\
\hline & NMBA (Rocuronium) & 59 & $\geq 4 \% \mathrm{CD} 63+$ & 80 & 96 & {$[65]$} \\
\hline & $\begin{array}{l}\text { Quinolones (ciprofloxacin, moxifloxacin and } \\
\text { levofloxacin) }\end{array}$ & 63 & $\begin{array}{l}\geq 5 \% \mathrm{CD} 63+ \\
\mathrm{CD} 203 \mathrm{c} \mathrm{SI} \geq 2\end{array}$ & 71.1 & 88 & {$[66]$} \\
\hline \multirow[t]{2}{*}{ Venom } & Wasp & 34 & $\begin{array}{l}\text { Determined but not } \\
\text { reported }\end{array}$ & 85.3 & 83.3 & {$[67]$} \\
\hline & Bee & 23 & $\begin{array}{l}\text { Determined but not } \\
\text { reported }\end{array}$ & 91.3 & 90.0 & {$[67]$} \\
\hline \multirow[t]{3}{*}{ Airborne } & Birch pollen & 62 & \multicolumn{3}{|c|}{$\begin{array}{l}\text { Response to AIT assessed using the BAT with results } \\
\text { expressed as basophil allergen threshold sensitivity }\end{array}$} & {$[68]$} \\
\hline & Timothy grass pollen & 24 & \multicolumn{3}{|c|}{$\begin{array}{l}\text { Response to AIT assessed using the BAT with results } \\
\text { expressed as basophil allergen threshold sensitivity }\end{array}$} & [69] \\
\hline & D. pteronyssinus & 13 & Not determined & 85 & 93 & {$[70 \bullet]$} \\
\hline
\end{tabular}


been suggested that the BAT may be able to identify the component of a vaccine responsible for immune-mediated adverse reactions [73] and to confirm whether an adverse reaction following transfusion of blood components is immunemediated [74-76].

The application of BAT in drug allergy goes further than standard diagnosis to possibly serving as a biomarker for anaphylaxis following drug desensitization. Drug desensitization is imperative for allergic patients requiring full therapeutic doses of lifesaving medication [77] and follows a step-wise protocol administering incremental doses of the drug [77]. For instance, BAT has been used to successfully identify patients allergic to platinum compounds with high risk of adverse reactions during drug desensitization with increased CD203c expression being indicative [78].

\section{BAT in the Diagnosis of Chronic Urticaria}

Chronic urticaria (CU) is largely idiopathic and often spontaneous and exhibits heterogeneity in induction, duration and mechanisms. A subset of CU patients have an autoimmune pathophysiology due to the presence of autoantibodies towards IgE or its high affinity receptor FceRI [79]. Moreover, the presence of anti-DsDNA antibodies, IgE and IgG targetted towards thyroid peroxidase have been identified in the sera of CU patients $[80,81]$. The confirmation of the autoimmune nature of $\mathrm{CU}$ demands a functional assay for diagnosis, for which the autologous serum skin test (ASST) has been relied upon. However, this is an in vivo test with a risk of accidental infection and whom test results do not always correlate with other in vitro assays $[82,83]$. Therefore, the BAT has been suggested as an in vitro surrogate for ASST, to diagnose and monitor patients with suspected CU. In previous studies, both CD63 and CD203c expression on the surface of basophils was increased following stimulation with sera from $\mathrm{CU}$ patients and BAT showed to be a functional test for the detection of active autoantibodies $[84,85]$. A recent study has shown that both ASST+/BAT+ urticaria patients often showed the most active disease state, in line with urticaria activity score (UAS). Thirty-two percent of ASST+/BAT+ patients, as opposed to $16 \%$ ASST+/BAT - patients required higher dose of antihistamines joint with third-line treatment (cyclosporine A or omalizumab) [86].

\section{BAT in the Diagnosis of Venom Allergy}

BAT reports both high sensitivity (85-100\%) and specificity $(83-100 \%)$ to diagnose hymenoptera venom allergy $[67,87$, 88]; however, testing for $\operatorname{sIgE}$ to the major allergens of bee and wasp venoms Api $\mathrm{m} 1$ and Ves v 5, respectively, reduced the impact of BAT in a large number of suspected cases. Still, BAT has found greatest success in venom allergy when solving unique diagnostic issues. For instance, a small proportion of patients with a clinical history of venom allergy report undetectable sIgE and negative skin tests. However, current guidelines do not advise on how to pursue diagnosis in these patients, further complicated by the unethical nature of sting provocation tests under these circumstances. BAT has proven effective in diagnosing approximately $80 \%$ of these patients, a marked improvement when diagnosing venom allergy with skin tests alone [89].

Another nuance of the diagnosis of hymenoptera venom allergy is the double positivity to both wasp and bee venom, where up to $60 \%$ of patients exhibit sIgE to both. In order to progress to venom immunotherapy (VIT), determination of the responsible allergen is imperative. The BAT consistently demonstrates lowest levels of double positivity when compared to other diagnostic methods and where double positivity is apparent, BAT is often able to identify the dominant allergen [90, 91]. Interestingly, sIgE determination to Api $\mathrm{m} 1$ and Ves v 5 reduces true double sensitization to $50 \%$ of cases of double positivity, but BAT still appears to add extra information [92•]. This suggests that assessing basophil reactivity utilizing these recombinant allergens as stimuli may be key in determining the culprit allergen source.

\section{BAT in the Diagnosis of Respiratory Allergy}

Allergic reactions to inhaled allergens are heterogeneous and can be complex due to the diversity of potential allergens that patients are naturally exposed to and the number of tissues that can be affected in a localized manner. sIgE quantification and SPT have long been considered sufficient to support the diagnosis of respiratory allergies; however, patients who suffer from local allergic rhinitis can have undetectable levels of sIgE and negative skin tests, making it hard to differentiate between allergic and nonallergic rhinitis. In these patients, BAT has proved more sensitive and able to diagnose IgE-mediated allergy despite the apparent absence of allergen-sIgE systemically [70 •]. Moreover, BAT has been used to explore unique aspects of allergic rhinitis and allergic asthma with basophil sensitivity (as expressed by CD-sens or EC50) showing concordance with nasal provocation titre [93] and bronchial provocation threshold respectively, confirming the clinical relevance of the allergen in driving the respiratory symptoms [94].

\section{BAT in the Follow-up of Patients Submitted to Allergen-Specific Immunotherapy and Other Immunomodulatory Treatments}

Determining basophil response to allergens is a powerful tool when monitoring the effects of allergen-specific immunotherapy (AIT) and also of other immunomodulatory treatments, 
such as anti-IgE $[93,95,96]$. Basophil sensitivity (as measured by CS-sens) has shown to be reduced following AIT to aeroallergens such as birch pollen $[97,98]$ and timothy grass pollen [99], and following AIT to insect venom [100, 101]. A drop in basophil sensitivity has also been reported following treatment with omalizumab across a range of allergies including allergy to peanut, cat and Aspergillus [102-104]. Interestingly, individuals with a higher antibodyspecific activity (higher percentage of allergen-specific IgE), displayed a greater efficacy to anti-IgE treatment, as determined by BAT [103]. This association is rational, as a higher percentage of allergen-specific IgE means it is more readily decreased following omalizumab administration. However, the intrinsic sensitivity of the basophil itself also appears to be modified during anti-IgE therapy, and competes with antibody specific activity, to alter the basophils response to challenge. The intrinsic sensitivity of a basophil, can be correlated with the expression of basophil spleen tyrosine kinase (Syk), an enzyme essential for IgE-mediated histamine release, and appears to increase during omalizumab treatment [105••]. This is counterintuitive to the overall decrease in basophil (allergen threshold) sensitivity as previously described in response to omalizumab, but means Syk expression could be a potential biomarker for predicting the clinical efficacy of omalizumab [106••].

\section{Using the Basophil Activation Test as a Tool to Explore the Immune Mechanisms of Allergic Disease}

The BAT transitions between the clinic and the laboratory in part due to its preservation of complex patient phenotypes, but also to the diverse immunological targets which can be assessed using this assay (Fig. 1). IgE-mediated basophil activation follows sensitization in which $\operatorname{IgE}$ binds to FceRI with high affinity and occurs when stimulation allergen or anti-IgE antibodies results in cross-linking of IgE molecules, phosphorylation of immunoreceptor tyrosine-based activation motif (ITAMs) in the intracellular portion of the beta and gamma chains of FceRI and subsequent cascade of phosphorylation of components of the intracellular activatory signalling pathway. Parallel inhibitory components can also be phosphorylated depending on concomitant co-stimulation, namely of immunoreceptor tyrosine-based inhibition motif (ITIM)associated receptors on the surface of basophils and may have an important role in basophil regulation. One of the inhibitory receptors of interest in antibody-mediated responses is CD32B, which can bind IgG and potentially allow crosslinking between IgE and IgG and suppress IgE-mediated basophil activation. IgG and other antibody isotypes other than $\operatorname{IgE}$ can interfere with allergen- $\operatorname{IgE}$ interaction also by blocking and competing for binding to the allergen in the extracellular space. [107, 108]

The key to the success of BAT in understanding the mechanisms of allergic disease is the ability to characterize the surface proteins expressed by basophils and how these modulate the response to allergen stimulation or challenge. The BAT allows for FceRI expression to be quantified [109, 110] as well as the expression of other Fcgamma receptors (CD16, CD32, CD64) in the steady state and also in response to activation or challenge $[111,112]$. The inhibitory potential of $\mathrm{CD} 32$ isoforms has been investigated using the BAT, revealing a complex system in which combinations of $\operatorname{IgG}$ isotypes and $\mathrm{IgG}$ concentrations elicit different levels of histamine release following blocking of CD32A or CD32B. Expression of Fcgamma receptors on basophils has been investigated in the context of allergy, for instance Meknache et al. [113] observing a lower expression of Fc $\gamma$ RIIIB on basophils from atopic dermatitis patients compared to patients with allergic rhinitis, asthma or chronic urticaria. The importance of Fcgamma receptor expression may have wider implications, as basophils from myelogenous leukaemia patients have an aberrant expression of CD64 [114]. The functional implications of these studies have yet to be fully elucidated.

Similarly, it is possible to measure receptor-bound antibodies on the surface of effector cells [115]. A detailed study by Eggel et al. [116] investigated the expression of surface-bound IgE in response to omalizumab treatment. The loss of surfacebound $\operatorname{IgE}$ mediated by omalizumab treatment resulted in ablated basophil activation, accompanied by the downregulation of FceRI $\alpha$ from the surface of basophils and a reduction in basophil numbers. The re-sensitization of basophils was performed by stripping surface IgE followed by addition of allergen-specific IgE before allergen challenge. The reintroduction of $\operatorname{IgE}$ induced the activation of basophils, further emphasizing the key mechanism of IgE-FceRI-mediated allergy. Furthermore, the authors expanded this model to test the effectiveness of other IgE inhibitors, utilizing the BAT to compare therapeutics under identical experimental conditions.

Basophil response to allergen stimulation can be modulated by the characteristics of allergen-specific IgE that is bound to its receptors, namely its concentration, specificity, clonality and affinity for allergen and this immunomodulation can be studied in vitro $[117,118]$. Christensen et al. generated 31 Der p 2-specific recombinant IgEs and showed that specificity and specific activity influence basophil reactivity whereas affinity and clonality influence basophil sensitivity [119•]. In order to improve our understanding of basophil response to allergen, using single allergens or epitope-containing peptides can add valuable information to the results obtained with allergen extracts [120]. Hayen et al. compared basophil responses to recombinant isoforms of Ara h2, Ara h 6, Ara h 7 and crude peanut extract, implicating Ara h 7.0201 as a dominant 


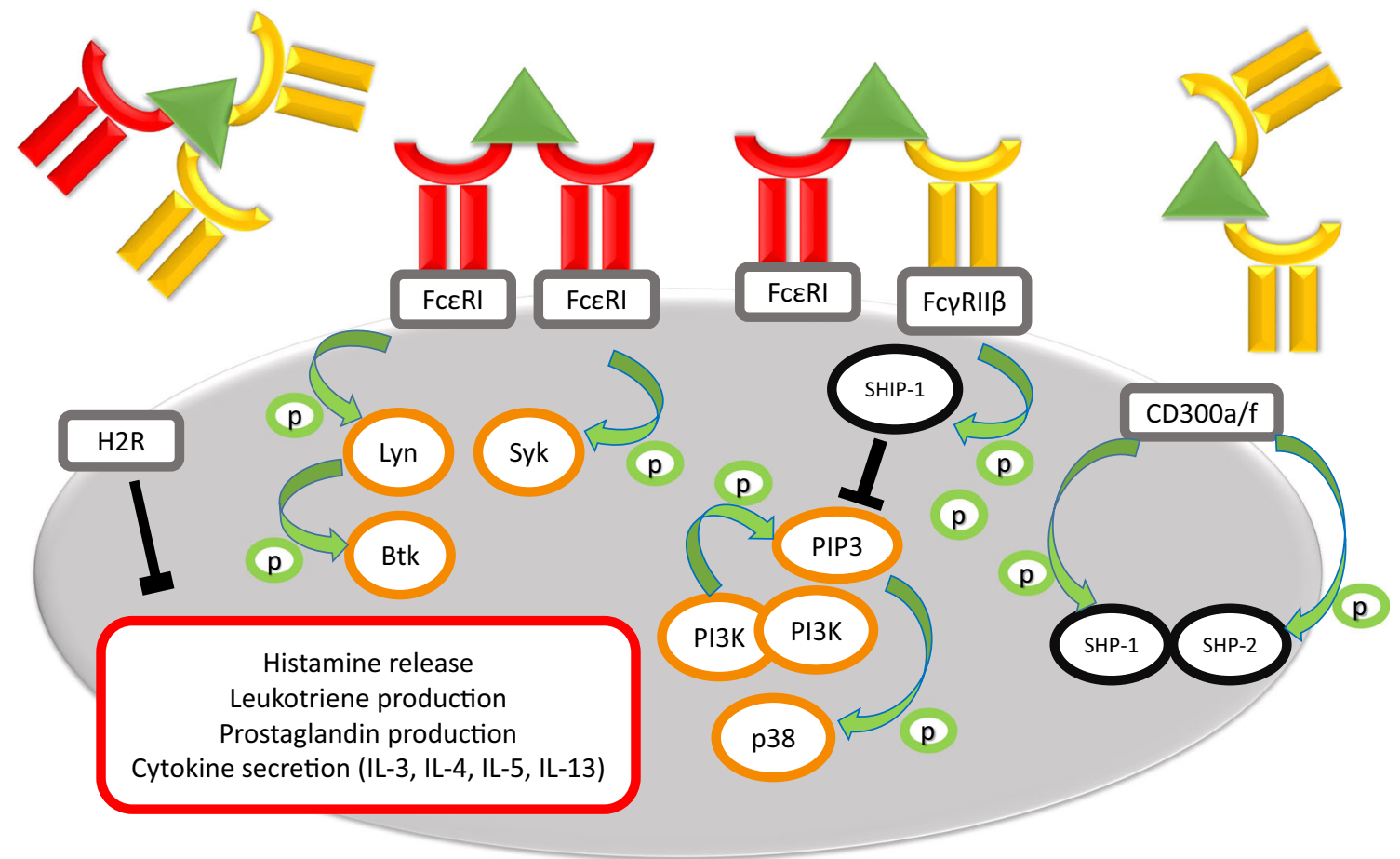

Fig. 1 Mechanisms of basophil response to allergens. A schematic diagram of basophil activation/inhibition in response to antibody crosslinking with allergen. IgE (red) and/or IgG (yellow) ligate cell surface receptors (grey boxes) and bind allergen (green triangles), inducing phosphorylation (green arrows/circles) of activatory (orange circles) or inhibitory (black circles) signalling proteins. Activation of basophils induces the secretion of potent cell mediators (red box), unless inhibited by intracellular processes (black "T") epitope for peanut allergy [121]. This work was built upon previous work on peanut allergy $[118,120]$ and additional studies have been performed investigating other foods [122, 123]. Greater understanding of peptides and epitopes which elicit allergic responses are key for both improved diagnostic tests and potential novel treatments.

Basophil activation can occur in an IgE-independent manner and the BAT can be performed to confirm the mechanism of activation to allergen. For instance, Aranda et al. tested whether basophil activation to quinolones resulted from an IgE-mediated mechanism using the PI3K inhibitor wortmannin [66]. The addition of wortmannin to the BAT experiments inhibited basophil activation to ciprofloxacin, moxifloxacin, levofloxacin and anti-IgE treatment, but inhibition was not observed with fMLP treatment [66], confirming the IgE-mediated nature of the reactions to the quinolones.

The BAT can also be used to explore the mechanisms of AIT at the basophil level. Reduction in basophil reactivity and in basophil sensitivity have both been reported with this treatment in patients with allergy to respiratory, food and venom allergens [99]. Remarkably, during oral peanut immunotherapy, the reduction in basophil reactivity was observed not only to the culprit allergen but also to a bystander allergen (e.g. egg) and IgE-mediated but not non-IgE mediated controls, suggesting basophil anergy [124•]. A study of allergic rhinitis patients sensitized to house dust mite (HDM) and mugwort showed that while desensitization was achieved to mugwort, no change was seen in reactivity to HDM after 24 months of AIT [125]. Discrepancies between study results may be in part due to natural allergen exposure (daily ingestion versus seasonal exposure), nature of the allergen molecules and route of administration [126], with oral IT to peanut performed by Thyagarajan et al. [124•] and subcutaneous IT performed by Kim et al. [126].

A number of studies have directly linked AIT to changes in immunoglobulin levels that in turn reduce basophil sensitivity. In particular, the significant increase in serum IgG in response to immunotherapy reduces basophil sensitivity, probably through the competition for allergen binding [98, 127, 128]. IgG4 in particular is regarded as possibly having an 'immunoregulatory' role, inhibiting allergic responses and maintaining immunological tolerance. Using a passive sensitization BAT in which IgE stripping from the receptors on the surface of basophils is followed by addition of patients' serum, Santos et al. [129] revealed the inhibitory role of allergen-specific IgG4 in peanut-sensitized but tolerant individuals and peanut-allergic individuals treated with oral peanut immunotherapy. Chan et al. [130] identified IgG antibodies specific for soluble IgE in serum and IgE bound to FceRI in non-allergic asthmatic patients. IgE binding of allergen was inhibited in sera containing IgE-specific IgG molecules, while depletion of $\mathrm{IgG}$ from sera ablated the inhibition of basophil activation. 
Thus, the BAT has elucidated that there are multiple potential mechanisms of basophil inhibition which are mediated by IgG-isotype antibodies.

The relevance of receptors not commonly associated with IgE can also be investigated using the BAT. Ligation of histamine receptors expressed by basophils (H1R, H2R and H3R) have been shown to induce basophil activation [16] which may be relevant in IT directed to insect venom [131]. Suppression of basophils mediated by histamine receptor 2 (HR2) has been proposed as an alternative mechanism of 'immuno-dampening' following immunotherapy [131]. Another inhibitory receptor of interest is CD300a (IRp60) which is upregulated in response to IgE/FceRI cross-linking [10]. TSLP receptor has recently been identified as being upregulated by basophils in allergic rhinitis patients in response to allergen challenge [11], adding to the growing number of receptors implicated in allergic responses beyond FceRI.

Although IgE:FceRI-mediated basophil activation has been established, the signalling events leading to CD63 upregulation and basophil degranulation are yet to be fully elucidated. The BAT allows for the phosphorylation of key activatory or inhibitory intracellular signalling proteins to be assessed simultaneously and in relation to CD63 and CD203c upregulation [21]. Verweij et al. [22] implicated STAT5 signalling as an activator of basophils in response to birch pollen ( $\mathrm{rBet} v \mathrm{1}$ ), but intriguingly, this required the presence of IL-3. Christensen et al. [12] investigated the role of signalling proteins in the context of AIT. Desensitized basophils displayed significantly reduced phosphorylated p38MAPK, which in an allergen-specific manner, resulted in reduced activation during allergen challenge. Changes in Syk expression via IgE in response to omazulimab treatment may also contribute to inhibition of allergic responses [13], but further work is required to understand the complex signalling pathways associated with basophil activation and inhibition and their modulation following allergen stimulation.

\section{Conclusions}

The BAT reproduces IgE-mediated allergic reactions in vitro, is a useful system for both clinical and research applications and has surmounted the old mediator release assays. Clinically, it can support the diagnosis of IgE-mediated allergic conditions and monitor patients over time and their response to immunomodulatory treatments. For research, BAT offers endless possibilities of studying the various components of the IgE-mediated allergic reaction and their modification, allowing dissection of the mechanisms of allergy and its suppression to improve our understanding and pave the way for the discovery of new targets for treatment and possibly prevention of allergic disease.

\section{Compliance with Ethical Standards}

Conflict of Interest Dr. Santos reports grants from Medical Research Council, NIAID/Immune Tolerance Network, Asthma UK; personal fees from Thermo Scientific, Nutricia, InfoMed and Buhlmann other from National Institute of Health (NIH) and National Institute for Health Research (NIHR), European Academy of Allergy and Clinical Immunology (EAACI), British Society of Allergy and Clinical Immunology (BSACI), Academy of Medical Sciences, Portuguese Society of Allergy and Clinical Immunology (SPAIC), Spanish Society of Allergy and Clinical Immunology (SEAIC), French Meeting of Molecular Allergology, Swiss Society of Allergology and Clinical Immunology and French Society of Immunology, outside the submitted work. The other authors declare no conflicts of interest relevant to this manuscript.

Human and Animal Rights and Informed Consent This article does not contain any studies with human or animal subjects performed by any of the authors.

Open Access This article is distributed under the terms of the Creative Commons Attribution 4.0 International License (http:// creativecommons.org/licenses/by/4.0/), which permits unrestricted use, distribution, and reproduction in any medium, provided you give appropriate credit to the original author(s) and the source, provide a link to the Creative Commons license, and indicate if changes were made.

\section{References}

Papers of particular interest, published recently, have been highlighted as:

- Of importance

•. Of major importance

1. Demoly P, Lebel B, Arnoux B. Allergen-induced mediator release tests. Allergy. 2003;58(7):553-8.

2. MacGlashan DW Jr. Basophil activation testing. J Allergy Clin Immunol. 2013 Oct;132(4):777-87.

3. Metcalfe DD, Pawankar R, Ackerman SJ, Akin C, Clayton F, Falcone FH, et al. Biomarkers of the involvement of mast cells, basophils and eosinophils in asthma and allergic diseases. World Allergy Org J. 2016;9:7.

4. Hoffmann HJ, Santos AF, Mayorga C, Nopp A, Eberlein B, Ferrer $\mathrm{M}$, et al. The clinical utility of basophil activation testing in diagnosis and monitoring of allergic disease. Allergy. 2015;70(11): 1393-405 A recent position paper from the European Academy of Allergy and Clinical Immunology addressing the use of BAT in the clinic and how it can help patient management.

5. Steiner M, Huber S, Harrer A, Himly M. The evolution of human basophil biology from neglect towards understanding of their immune functions. Biomed Res Int. 2016;16.

6. Hausmann OV, Gentinetta T, Fux M, Ducrest S, Pichler WJ, Dahinden CA. Robust expression of CCR3 as a single basophil selection marker in flow cytometry. Allergy. 2011;66(1):85-91.

7. Monneret G. CCR 3 for basophil activation test: a necessary but insufficient step. Clin Exp Allergy. 2010;40(6):953 author reply 4.

8. Eberlein B, Hann R, Eyerich S, Pennino D, Ring J, SchmidtWeber CB, et al. Optimizing of the basophil activation test: 
comparison of different basophil identification markers. Cytometry B Clin Cytom. 2015;88(3):183-9.

9. Ducrest S, Meier F, Tschopp C, Pavlovic R, Dahinden CA. Flowcytometric analysis of basophil counts in human blood and inaccuracy of hematology analyzers. Allergy. 2005;60(11):1446-50.

10. Sabato V, Boita M, Shubber S, Bridts CH, Shibuya A, De Clerck LS, et al. Mechanism of phosphatidylserine inhibition of IgE/ FcepsilonRI-dependent anaphylactic human basophil degranulation via CD300a. J Allergy Clin Immunol. 2014;134(3):734-7 e3.

11. Arai T, Sakurai D, Iinuma $T$, Nakagawa $T$, Yonekura $S$, Okamoto Y. Basophils from allergic rhinitis patients show allergen-specific upregulation of thymic stromal lymphopoietin receptor. Ann Allergy Asthma Immunol. 2018;120(2):155-63.

12. Witting Christensen SK, Kortekaas Krohn I, Thuraiaiyah J, Skjold T, Schmid JM, Hoffmann HJ. Sequential allergen desensitization of basophils is non-specific and may involve p38 MAPK. Allergy. 2014;69(10):1343-9.

13. Zaidi AK, Saini SS, Macglashan DW Jr. Regulation of Syk kinase and FcRbeta expression in human basophils during treatment with omalizumab. J Allergy Clin Immunol. 2010;125(4):902-8 e7.

14. Santos AF, Shreffler WG. Road map for the clinical application of the basophil activation test in food allergy. Clin Exp Allergy. 2017;47(9):1115-24.

15. Monneret G. Is this time for CRTH2/DP2 in a flow cytometric basophil activation test? Clin Exp Allergy. 2008;38(7):1239-40.

16. Mommert S, Kleiner S, Gehring M, Eiz-Vesper B, Stark H, Gutzmer R, et al. Human basophil chemotaxis and activation are regulated via the histamine H4 receptor. Allergy. 2016;71(9): 1264-73.

17.• Knol EF, Mul FP, Jansen H, Calafat J, Roos D. Monitoring human basophil activation via CD63 monoclonal antibody 435. J Allergy Clin Immunol. 1991;88(3 Pt 1):328-38 Seminal paper identifying CD63 as a viable surrogate marker for basophil degranulation. CD63 is now a standard measure of basophil activation the context of BAT.

18. Hennersdorf F, Florian S, Jakob A, Baumgartner K, Sonneck K, Nordheim A, et al. Identification of CD13, CD107a, and CD164 as novel basophil-activation markers and dissection of two response patterns in time kinetics of IgE-dependent upregulation. Cell Res. 2005;15(5):325-35.

19. Suzukawa M, Komiya A, Yoshimura-Uchiyama C, Kawakami A, Koketsu R, Nagase H, et al. IgE- and FceRI-mediated enhancement of surface CD69 expression in basophils: role of low-level stimulation. Int Arch Allergy Immunol. 2007;143(Suppl. 1):56-9.

20. Yoshimura C, Yamaguchi M, Iikura M, Izumi S, Kudo K, Nagase $\mathrm{H}$, et al. Activation markers of human basophils: CD69 expression is strongly and preferentially induced by IL-3. J Allergy Clin Immunol. 2002;109(5):817-23.

21. Ebo DG, Dombrecht EJ, Bridts CH, Aerts NE, de Clerck LS, Stevens WJ. Combined analysis of intracellular signalling and immunophenotype of human peripheral blood basophils by flow cytometry: a proof of concept. Clin Exp Allergy. 2007;37(11):1668-75.

22. Verweij MM, Sabato V, Nullens S, Bridts CH, De Clerck LS, Stevens WJ, et al. STAT5 in human basophils: IL-3 is required for its FcepsilonRI-mediated phosphorylation. Cytometry B Clin Cytom. 2012;82(2):101-6.

23. Mukai K, Gaudenzio N, Gupta S, Vivanco N, Bendall SC, Maecker HT, et al. Assessing basophil activation by using flow cytometry and mass cytometry in blood stored 24 hours before analysis. J Allergy Clin Immunol. 2017;139(3):889-99 e11 Study on the impact of different methodologies in the results of the BAT using flow cytometry and the use of CyTOF technology to assess basophil activation in response to allergen.

24. Mukai K, Chinthrajah RS, Nadeau KC, Tsai M, Gaudenzio N, Galli SJ. A new fluorescent-avidin-based method for quantifying basophil activation in whole blood. J Allergy Clin Immunol. 2017;140(4):1202-6 e3.

25. Gibbs BF, Papenfuss K, Falcone FH. A rapid two-step procedure for the purification of human peripheral blood basophils to near homogeneity. Clin Exp Allergy. 2008;38(3):480-5.

26. Ebo DG, Bridts CH, Hagendorens MM, Aerts NE, De Clerck LS, Stevens WJ. Basophil activation test by flow cytometry: present and future applications in allergology. Cytometry B Clin Cytom. 2008;74(4):201-10.

27. Hoffmann HJ, Knol EF, Ferrer M, Mayorga L, Sabato V, Santos AF, et al. Pros and cons of clinical basophil testing (BAT). Curr Allergy Asthma Rep. 2016;16(8):56.

28. Sturm GJ, Kranzelbinder B, Sturm EM, Heinemann A, GroseljStrele A, Aberer W. The basophil activation test in the diagnosis of allergy: technical issues and critical factors. Allergy. 2009;64(9): 1319-26.

29. Kwok M, Lack G, Santos AF. Improved standardisation of the whole blood basophil activation test to peanut. Clin Transl Allergy. 2017;8((Suppl 2)(26)):15-6.

30. Glaumann S, Nopp A, Johansson SG, Rudengren M, Borres MP, Nilsson C. Basophil allergen threshold sensitivity, CD-sens, IgEsensitization and DBPCFC in peanut-sensitized children. Allergy. 2012;67(2):242-7.

31. Bühring HJ, Streble A, Valent P. The basophil-specific ectoenzyme E-NPP3 (CD203c) as a marker for cell activation and allergy diagnosis. Int Arch Allergy Immunol. 2004;133(4): 317-29.

32. Uyttebroek AP, Sabato V, Faber MA, Cop N, Bridts CH, Lapeere $\mathrm{H}$, et al. Basophil activation tests: time for a reconsideration. Expert Rev Clin Immunol. 2014 Oct;10(10):1325-35.

33. Santos AF, Lack G. Basophil activation test: food challenge in a test tube or specialist research tool? Clin Transl Allergy [journal article]. 2016;6(1):10.

34. Johansson SGO, Nopp A, Hage M, Olofsson N, Lundahl J, Wehlin L, et al. Passive IgE-sensitization by blood transfusion. Allergy. 2005;60(9):1192-9.

35. Patil SU, Shreffler WG. Immunology in the clinic review series; focus on allergies: basophils as biomarkers for assessing immune modulation. Clin Exp Immunol. 2012;167(1):59-66.

36. Eberlein B, Leon Suarez I, Darsow U, Rueff F, Behrendt H, Ring J. A new basophil activation test using CD63 and CCR3 in allergy to antibiotics. Clin Exp Allergy. 2010;40(3):411-8.

37.• Patil SU, Calatroni A, Schneider M, Steinbrecher J, Smith N, Washburn C, et al. Data-driven programmatic approach to analysis of basophil activation tests. Cytometry B Clin Cytom. 2017. This study introduces a new automated approach for analysing the flow cytometry data when performing the BAT, which has the potential to enhance standardisation and efficiency of data analyses in the future.

38. Boyce JA, Assa'ad A, Burks AW, Jones SM, Sampson HA, Wood RA, et al. Guidelines for the diagnosis and management of food allergy in the United States: summary of the NIAID-sponsored expert panel report. J Am Acad Dermatol. 2011;64(1):175-92.

39. Krishna MT, Ewan PW, Diwakar L, Durham SR, Frew AJ, Leech $\mathrm{SC}$, et al. Diagnosis and management of hymenoptera venom allergy: British Society for Allergy and Clinical Immunology (BSACI) guidelines. Clin Exp Allergy. 2011;41(9):1201-20.

40. Mirakian R, Ewan PW, Durham SR, Youlten LJ, Dugue P, Friedmann PS, et al. BSACI guidelines for the management of drug allergy. Clin Exp Allergy. 2009;39(1):43-61.

41. Scadding GK, Kariyawasam HH, Scadding G, Mirakian R, Buckley RJ, Dixon T, et al. BSACI guideline for the diagnosis and management of allergic and non-allergic rhinitis (revised edition 2017; first edition 2007). Clin Exp Allergy. 2017;47(7):85689. 
42. Stiefel G, Anagnostou K, Boyle RJ, Brathwaite N, Ewan P, Fox AT, et al. BSACI guideline for the diagnosis and management of peanut and tree nut allergy. Clin Exp Allergy. 2017;47(6):719-39.

43. Roberts G, Lack G. Diagnosing peanut allergy with skin prick and specific IgE testing. J Allergy Clin Immunol. 2005;115(6):12916.

44. Lieberman JA, Cox AL, Vitale M, Sampson HA. Outcomes of office-based, open food challenges in the management of food allergy. J Allergy Clin Immunol. 2011;128(5):1120-2.

45.• Santos AF, Douiri A, Bécares N, Wu S-Y, Stephens A, Radulovic $\mathrm{S}$, et al. Basophil activation test discriminates between allergy and tolerance in peanut-sensitized children. J Allergy Clin Immunol. 2014;134(3):645-52 Diagnostic study looking at the utility of the BAT in peanut allergy in a large cohort of children, including an additional prospective cohort for validation of diagnostic cut-offs.

46. Perry TT, Matsui EC, Conover-Walker MK, Wood RA. Risk of oral food challenges. J Allergy Clin Immunol. 2004;114(5):1164-8.

47. Rubio A, Vivinus-Nébot M, Bourrier T, Saggio B, Albertini M, Bernard A. Benefit of the basophil activation test in deciding when to reintroduce cow's milk in allergic children. Allergy. 2010;66(1): 92-100.

48. Ocmant A, Mulier S, Hanssens L, Goldman M, Casimir G, Mascart F, et al. Basophil activation tests for the diagnosis of food allergy in children. Clin Exp Allergy. 2009;39(8):1234-45.

49. Elizur A, Appel MY, Nachshon L, Levy MB, Epstein-Rigbi N, Golobov K, et al. NUT Co Reactivity - ACquiring Knowledge for Elimination Recommendations (NUT CRACKER) study. Allergy. 2017;73(3):593-601.

50. van Erp FC, Knol EF, Pontoppidan B, Meijer Y, van der Ent CK, Knulst AC. The IgE and basophil responses to Ara h 2 and Ara h 6 are good predictors of peanut allergy in children. J Allergy Clin Immunol. 2017;139(1):358-60 e8.

51. Song Y, Wang J, Leung N, Wang LX, Lisann L, Sicherer SH, et al. Correlations between basophil activation, allergen-specific IgE with outcome and severity of oral food challenges. Ann Allergy Asthma Immunol. 2015;114(4):319-26.

52. Santos AF, Du Toit G, Douiri A, Radulovic S, Stephens A, Turcanu V, et al. Distinct parameters of the basophil activation test reflect the severity and threshold of allergic reactions to peanut. J Allergy Clin Immunol. 2015;135(1):179-86.

53. Chinthrajah RS, Purington N, Andorf S, Rosa JS, Mukai K, Hamilton R, et al. Development of a tool predicting severity of allergic reaction during peanut challenge. Ann Allergy Asthma Immunol. 2018;121(1):69-76.e2.

54. Mayorga C, Sanz ML, Gamboa PM, Garcia BE, Caballero MT, Garcia JM, et al. In vitro diagnosis of immediate allergic reactions to drugs: an update. J Investig Allergol Clin Immunol. 2010;20(2): 103-9.

55. Ebo Didier G, Bridts Chris H, Stevens WJ. IgE-mediated anaphylaxis from chlorhexidine: diagnostic possibilities. Contact Dermatitis. 2006;55(5):301-2.

56. Cabrera-Freitag P, Gastaminza G, Goikoetxea MJ, Lafuente A, De La Borbolla JM, Sanz ML. Immediate allergic reaction to atropine in ophthalmic solution confirmed by basophil activation test. Allergy. 2009;64(9):1388-9.

57. Sanz ML, Gamboa PM, Antépara I, Uasuf C, Vila L, GarciaAvilés C, et al. Flow cytometric basophil activation test by detection of CD63 expression in patients with immediate-type reactions to betalactam antibiotics. Clin Exp Allergy. 2002;32(2):277-86.

58. Torres MJ, Padial A, Mayorga C, Fernández T, Sanchez-Sabate E, Cornejo-García JA, et al. The diagnostic interpretation of basophil activation test in immediate allergic reactions to betalactams. Clin Exp Allergy. 2004;34(11):1768-75.
59. Ben Said B, Berard F, Bienvenu J, Nicolas JF, Rozieres A. Usefulness of basophil activation tests for the diagnosis of IgEmediated allergy to quinolones. Allergy. 2009;65(4):535-6.

60. Rouzaire P, Nosbaum A, Denis L, Bienvenu F, Bérard F, Cozon G, et al. Negativity of the basophil activation test in quinolone hypersensitivity: a breakthrough for provocation test decision-making. Int Arch Allergy Immunol. 2012;157(3):299-302.

61. Aranda A, Mayorga C, Ariza A, Doña I, Rosado A, Blanca-Lopez $\mathrm{N}$, et al. In vitro evaluation of IgE-mediated hypersensitivity reactions to quinolones. Allergy. 2011;66(2):247-54.

62. Monneret G, Benoit Y, Debard AL, Gutowski MC, Topenot I, Bienvenu J. Monitoring of basophil activation using CD63 and CCR3 in allergy to muscle relaxant drugs. Clin Immunol. 2002;102(2):192-9.

63. Dewachter P, Chollet-Martin S, Mouton-Faivre C, de Chaisemartin L, Nicaise-Roland P. Comparison of basophil activation test and skin testing performances in NMBA allergy. The Journal of Allergy and Clinical Immunology: In Practice. 2018.

64. Sato S, Tachimoto H, Shukuya A, Kurosaka N, Yanagida N, Utsunomiya T, et al. Basophil activation marker CD203c is useful in the diagnosis of hen's egg and cow's milk allergies in children. Int Arch Allergy Immunol. 2010;152(Suppl 1):54-61.

65. Leysen J, Bridts CH, De Clerck LS, Ebo DG. Rocuroniuminduced anaphylaxis is probably not mitigated by sugammadex: evidence from an in vitro experiment. Anaesthesia. 2011;66(6): 526-7.

66. Aranda A, Mayorga C, Ariza A, Dona I, Rosado A, Blanca-Lopez $\mathrm{N}$, et al. In vitro evaluation of IgE-mediated hypersensitivity reactions to quinolones. Allergy. $2011 \mathrm{Feb} ; 66(2): 247-54$.

67. Sturm GJ, Bohm E, Trummer M, Weiglhofer I, Heinemann A, Aberer W. The CD63 basophil activation test in Hymenoptera venom allergy: a prospective study. Allergy. 2004;59(10):1110-7.

68. Ceuppens JL, Bullens D, Kleinjans H, van der Werf J. Immunotherapy with a modified birch pollen extract in allergic rhinoconjunctivitis: clinical and immunological effects. Clin Exp Allergy. 2009;39(12):1903-9.

69. Schmid JM, Wurtzen PA, Dahl R, Hoffmann HJ. Early improvement in basophil sensitivity predicts symptom relief with grass pollen immunotherapy. J Allergy Clin Immunol. 2014;134(3): 741-4 e5.

70. Gomez E, Campo P, Rondon C, Barrionuevo E, Blanca-Lopez N, Torres MJ, et al. Role of the basophil activation test in the diagnosis of local allergic rhinitis. J Allergy Clin Immunol. 2013;132(4):975-6 e1-5. Study highlighting the sensitivity of the BAT in diagnosing allergic rhinitis in patients with no evidence of systemic allergen-specific IgE.

71. Laguna JJ, Bogas G, Salas M, Mayorga C, Dionicio J, GonzalezMendiola R, et al. The basophil activation test can be of value for diagnosing immediate allergic reactions to omeprazole. J Allergy Clin Immunol Pract. 2018;6(5):1628-36 e2.

72. Salas M, Fernández-Santamaría R, Mayorga C, Barrionuevo E, Ariza A, Posadas T, et al. Use of the basophil activation test may reduce the need for drug provocation in amoxicillin-clavulanic allergy. J Allergy Clin Immunol Pract. 2018;6(3):1010-18 e2. Large study on the use of BAT to diagnose immediate hypersensitivity to amoxicillin-clavulanic acid.

73. Herreros B, Méndez Y, Feo-Brito F, Urra JM. Usefulness of basophil activation test for the diagnosis of IgE mediated hypersensitivity to tetanus toxoid vaccine. J Immunol Methods. 2018;454: 86-8.

74. Kato H, Uruma M, Okuyama Y, Fujita H, Handa M, Tomiyama Y, et al. Incidence of transfusion-related adverse reactions per patient reflects the potential risk of transfusion therapy in Japan. Am J Clin Pathol. 2013;140(2):219-24. 
75. Sandler SG, Eder Anne F, Goldman M, Winters JL. The entity of immunoglobulin A-related anaphylactic transfusion reactions is not evidence based. Transfusion. 2014;55(1):199-204.

76. Okamura I, Matsuyama N, Yasui K, Hirayama F, Ikeda T. Clinical utility of the basophil activation test for analysis of allergic transfusion reactions: a pilot study. Vox Sang. 2017;112(2):114-21.

77. Castells M. Desensitization for drug allergy. Curr Opin Allergy Clin Immunol. 2006 Dec;6(6):476-81.

78. Giavina-Bianchi P, Galvão VR, Picard M, Caiado J, Castells MC. Basophil activation test is a relevant biomarker of the outcome of rapid desensitization in platinum compounds-allergy. J Allergy Clin Immunol Pract. 2017;5(3):728-36.

79. Kikuchi Y, Kaplan AP. Mechanisms of autoimmune activation of basophils in chronic urticaria. J Allergy Clin Immunol. 2001;107(6):1056-62.

80. Kashiwakura J, Hayama K, Fujisawa D, Sasaki-Sakamoto T, Terui $\mathrm{T}$, Ra C, et al. Significantly high levels of anti-dsDNA immunoglobulin $\mathrm{E}$ in sera and the ability of dsDNA to induce the degranulation of basophils from chronic urticaria patients. Int Arch Allergy Immunol. 2013;161(Suppl. 2):154-8.

81. Levy Y, Segal N, Weintrob N, Danon Y. Chronic urticaria: association with thyroid autoimmunity. Arch Dis Child. 2003;88(6): 517-9.

82. Niimi N, Francis DM, Kermani F, O'Donnell BF, Hide M, KobzaBlack A, et al. Dermal mast cell activation by autoantibodies against the high affinity IgE receptor in chronic urticaria. J Investig Dermatol. 1996;106(5):1001-6.

83. Bernstein JA, Lang DM, Khan DA, Craig T, Dreyfus D, Hsieh F, et al. The diagnosis and management of acute and chronic urticaria: 2014 update. J Allergy Clin Immunol. 2014;133(5):12707.e66.

84. Wedi B, Novacovic V, Koerner M, Kapp A. Chronic urticaria serum induces histamine release, leukotriene production, and basophil CD63 surface expression-inhibitory effects of antiinflammatory drugs. J Allergy Clin Immunol. 2000;105(3):55260 .

85. Yasnowsky KM, Dreskin SC, Efaw B, Schoen D, Vedanthan PK, Alam R, et al. Chronic urticaria sera increase basophil CD203c expression. J Allergy Clin Immunol. 2006;117(6):1430-4.

86. Curto-Barredo L, Yelamos J, Gimeno R, Mojal S, Pujol Ramon M, Giménez-Arnau A. Basophil activation test identifies the patients with chronic spontaneous Urticaria suffering the most active disease. Immun Inflamm Dis. 2016;4(4):441-5.

87. Erdmann SM, Sachs B, Kwiecien R, Moll-Slodowy S, Sauer I, Merk HF. The basophil activation test in wasp venom allergy: sensitivity, specificity and monitoring specific immunotherapy. Allergy. 2004;59(10):1102-9.

88. Eberlein-König B, Varga R, Mempel M, Darsow U, Behrendt H, Ring J. Comparison of basophil activation tests using CD63 or CD203c expression in patients with insect venom allergy. Allergy. 2006;61(9):1084-5.

89. Korošec P, Šilar M, Eržen R, Čelesnik N, Bajrović N, Zidarn M, et al. Clinical routine utility of basophil activation testing for diagnosis of Hymenoptera-allergic patients with emphasis on individuals with negative venom-specific IgE antibodies. Int Arch Allergy Immunol. 2013;161(4):363-8.

90. Eberlein-Konig B, Rakoski J, Behrendt H, Ring J. Use of CD63 expression as marker of in vitro basophil activation in identifying the culprit in insect venom allergy. J Investig Allergol Clin Immunol. 2004;14(1):10-6.

91. Sturm GJ, Jin C, Kranzelbinder B, Hemmer W, Sturm EM, Griesbacher A, et al. Inconsistent results of diagnostic tools hamper the differentiation between bee and vespid venom allergy. PLoS One. 2011;6(6):e20842.

92. Eberlein B, Krischan L, Darsow U, Ollert M, Ring J. Double positivity to bee and wasp venom: improved diagnostic procedure by recombinant allergen-based IgE testing and basophil activation test including data about cross-reactive carbohydrate determinants. J Allergy Clin Immunol. 2012;130(1):155-61. Study in hymenoptera venom allergy looking at the combined use of BAT and serology to confirm the diagnosis.

93. Nopp A, Johansson SGO, Ankerst J, Bylin G, Cardell LO, Grönneberg R, et al. Basophil allergen threshold sensitivity: a useful approach to anti-IgE treatment efficacy evaluation. Allergy. 2006;61(3):298-302.

94. Dahlén B, Nopp A, Johansson SGO, Eduards M, Skedinger M, Adédoyin J. Basophil allergen threshold sensitivity, CD-sens, is a measure of allergen sensitivity in asthma. Clin Exp Allergy. 2011;41(8):1091-7.

95. Mikkelsen S, Bibby BM, Dolberg MKB, Dahl R, Hoffmann HJ. Basophil sensitivity through CD63 or CD203c is a functional measure for specific immunotherapy. Clin Mol Allergy. 2010;8:2.

96. Nopp A, Cardell LO, Johansson SG, Oman H. CD-Sens: a biological measure of immunological changes stimulated by ASIT. Allergy. 2009;64(5):811-4.

97. Ceuppens JL, Bullens D, Kleinjans H, Van Der Werf J. Null n. immunotherapy with a modified birch pollen extract in allergic rhinoconjunctivitis: clinical and immunological effects. Clin Exp Allergy. 2009;39(12):1903-9.

98. Lalek N, Kosnik M, Silar M, Korosec P. Immunoglobulin Gdependent changes in basophil allergen threshold sensitivity during birch pollen immunotherapy. Clin Exp Allergy. 2010;40(8): 1186-93.

99. Schmid JM, Würtzen PA, Dahl R, Hoffmann HJ. Early improvement in basophil sensitivity predicts symptom relief with grass pollen immunotherapy. J Allergy Clin Immunol. 2014;134(3): 741-4.e5.

100. Žitnik Simona EK, Vesel T, Avčin T, Šilar M, Košnik M, Korošec P. Monitoring honeybee venom immunotherapy in children with the basophil activation test. Pediatr Allergy Immunol. 2011;23(2): 167-72.

101. Eržen R, Košnik M, Šilar M, Korošec P. Basophil response and the induction of a tolerance in venom immunotherapy: a long-term sting challenge study. Allergy. 2012;67(6):822-30.

102. Gernez Y, Tirouvanziam R, Yu G, Ghosn EEB, Reshamwala N, Nguyen T, et al. Basophil CD203c levels are increased at baseline and can be used to monitor omalizumab treatment in subjects with nut allergy. Int Arch Allergy Immunol. 2011;154(4):318-27.

103. Johansson SG, Nopp A, Oman H, Ankerst J, Cardell LO, Gronneberg R, et al. The size of the disease relevant $\operatorname{IgE}$ antibody fraction in relation to 'total-IgE' predicts the efficacy of anti-IgE (Xolair) treatment. Allergy. 2009;64(10):1472-7.

104. Voskamp AL, Gillman A, Symons K, Sandrini A, Rolland JM, O'Hehir RE, et al. Clinical efficacy and immunologic effects of omalizumab in allergic bronchopulmonary aspergillosis. J Allergy Clin Immunol Pract. 2015;3(2):192-9.

105.• MacGlashan DW Jr, Savage JH, Wood RA, Saini SS. Suppression of the basophil response to allergen during treatment with omalizumab is dependent on 2 competing factors. J Allergy Clin Immunol. 2012;130(5):1130-5 e5. Studies on the kinetics of basophil modifications induced by treatment with omalizumab.

106.• MacGlashan DW Jr, Saini SS. Syk expression and IgE-mediated histamine release in basophils as biomarkers for predicting the clinical efficacy of omalizumab. J Allergy Clin Immunol. 2017;139(5):1680-2 e10 Studies on the kinetics of basophil modifications induced by treatment with omalizumab.

107. Dodev TS, Bowen H, Shamji MH, Bax HJ, Beavil AJ, McDonnell $\mathrm{JM}$, et al. Inhibition of allergen-dependent IgE activity by antibodies of the same specificity but different class. Allergy. 2015;70(6): $720-4$.

108. Strait RT, Morris SC, Finkelman FD. IgG-blocking antibodies inhibit IgE-mediated anaphylaxis in vivo through both antigen 
interception and $\mathrm{Fc}$ gamma RIIb cross-linking. J Clin Invest. 2006;116(3):833-41.

109. MacGlashan D Jr, Lichtenstein LM, McKenzie-White J, Chichester K, Henry AJ, Sutton BJ, et al. Upregulation of FcepsilonRI on human basophils by IgE antibody is mediated by interaction of IgE with FcepsilonRI. J Allergy Clin Immunol. 1999;104(2 Pt 1):492-8.

110. Bax HJ, Bowen H, Dodev TS, Sutton BJ, Gould HJ. Mechanism of the antigen-independent cytokinergic SPE-7 IgE activation of human mast cells in vitro. Sci Rep. 2015;5:9538.

111. Kepley CL, Cambier JC, Morel PA, Lujan D, Ortega E, Wilson BS, et al. Negative regulation of FcepsilonRI signaling by FcgammaRII costimulation in human blood basophils. J Allergy Clin Immunol. 2000;106(2):337-48.

112. MacGlashan D Jr, Hamilton RG. Parameters determining the efficacy of CD32 to inhibit activation of FcepsilonRI in human basophils. J Allergy Clin Immunol. 2016;137(4):1256-8 e1-11.

113. Meknache N, Jonsson F, Laurent J, Guinnepain MT, Daeron M. Human basophils express the glycosylphosphatidylinositolanchored low-affinity IgG receptor FcgammaRIIIB (CD16B). J Immunol. 2009;182(4):2542-50.

114. Han X, Jorgensen JL, Brahmandam A, Schlette E, Huh YO, Shi Y, et al. Immunophenotypic study of basophils by multiparameter flow cytometry. Arch Pathol Lab Med. 2008;132(5):813-9.

115. MacGlashan D Jr. Subthreshold desensitization of human basophils re-capitulates the loss of Syk and FcepsilonRI expression characterized by other methods of desensitization. Clin Exp Allergy. 2012;42(7):1060-70.

116. Eggel A, Baravalle G, Hobi G, Kim B, Buschor P, Forrer P, et al. Accelerated dissociation of IgE-FcepsilonRI complexes by disruptive inhibitors actively desensitizes allergic effector cells. J Allergy Clin Immunol. 2014;133(6):1709-19 e8.

117. Johansson SG, Oman H, Nopp A, Pettersson S. The importance of IgE antibody levels in anti-IgE treatment. Allergy. 2006;61(10): 1216-9.

118. Beyer K, Ellman-Grunther L, Jarvinen KM, Wood RA, Hourihane J, Sampson HA. Measurement of peptide-specific IgE as an additional tool in identifying patients with clinical reactivity to peanuts. J Allergy Clin Immunol. 2003;112(1):202-7.

119. Christensen LH, Holm J, Lund G, Riise E, Lund K. Several distinct properties of the IgE repertoire determine effector cell degranulation in response to allergen challenge. J Allergy Clin Immunol. 2008;122(2):298-304 Elegant study looking at how the characteristics of IgE can modulate basophil response.

120. Koppelman SJ, de Jong GA, Laaper-Ertmann M, Peeters KA, Knulst AC, Hefle SL, et al. Purification and immunoglobulin Ebinding properties of peanut allergen Ara h 6: evidence for crossreactivity with Ara h 2. Clin Exp Allergy. 2005;35(4):490-7.
121. Hayen SM, Ehlers AM, den Hartog Jager CF, Garssen J, Knol EF, Knulst AC, et al. 2S protein Ara h 7.0201 has unique epitopes compared to other Ara h 7 isoforms and is comparable to $2 \mathrm{~S}$ proteins Ara h 2 and 6 in basophil degranulation capacity. Clin Exp Allergy. 2018.

122. Wallowitz ML, Chen RJ, Tzen JT, Teuber SS. Ses i 6, the sesame $11 \mathrm{~S}$ globulin, can activate basophils and shows cross-reactivity with walnut in vitro. Clin Exp Allergy. 2007;37(6):929-38.

123. Abramovitch JB, Kamath S, Varese N, Zubrinich C, Lopata AL, O'Hehir RE, et al. IgE reactivity of blue swimmer crab (Portunus pelagicus) tropomyosin, por $\mathrm{p} 1$, and other allergens; crossreactivity with black Tiger prawn and effects of heating. PLoS One. 2013;8(6):e67487.

124. Thyagarajan A, Jones SM, Calatroni A, Pons L, Kulis M, Woo CS, et al. Evidence of pathway-specific basophil anergy induced by peanut oral immunotherapy in peanut-allergic children. Clin Exp Allergy. 2012;42(8):1197-205. Study showing changes in basophil response induced by allergen and also non-allergen specific IgE-mediated stimulants, suggesting basophil anergy, during peanut oral immunotherapy.

125. Kim SH, Chung SJ, Kim JH, Lee SY, Kim BK, Lim KW, Chang YS. Changes in basophil activation during immunotherapy with house dust mite and mugwort in patients with allergic rhinitis. Asia Pac Allergy. 2018;8:e6.

126. Vonk MM, Wagenaar L, Pieters RHH, Knippels LMJ, Willemsen LEM, Smit JJ, et al. The efficacy of oral and subcutaneous antigen-specific immunotherapy in murine cow's milk and peanut allergy models. Clin Transl Allergy. 2017;7:35.

127. Shamji MH, Ljørring C, Francis JN, Calderon MA, Larché M, Kimber I, et al. Functional rather than immunoreactive levels of IgG4 correlate closely with clinical response to grass pollen immunotherapy. Allergy. 2011;67(2):217-26.

128. Wachholz PA, Soni NK, Till SJ, Durham SR. Inhibition of allergen-IgE binding to B cells by IgG antibodies after grass pollen immunotherapy. J Allergy Clin Immunol. 2003 Nov;112(5): 915-22.

129. Santos AF, James LK, Bahnson HT, Shamji MH, Couto-Francisco $\mathrm{NC}$, Islam S, et al. IgG4 inhibits peanut-induced basophil and mast cell activation in peanut-tolerant children sensitized to peanut major allergens. J Allergy Clin Immunol. 2015;135(5):1249-56.

130. Chan YC, Ramadani F, Santos AF, Pillai P, Ohm-Laursen L, Harper CE, et al. "Auto-anti-IgE": naturally occurring IgG antiIgE antibodies may inhibit allergen-induced basophil activation. J Allergy Clin Immunol. 2014;134(6):1394-401 e4.

131. Novak N, Mete N, Bussmann C, Maintz L, Bieber T, Akdis M, et al. Early suppression of basophil activation during allergenspecific immunotherapy by histamine receptor 2. J Allergy Clin Immunol. 2012;130(5):1153-8 e2. 